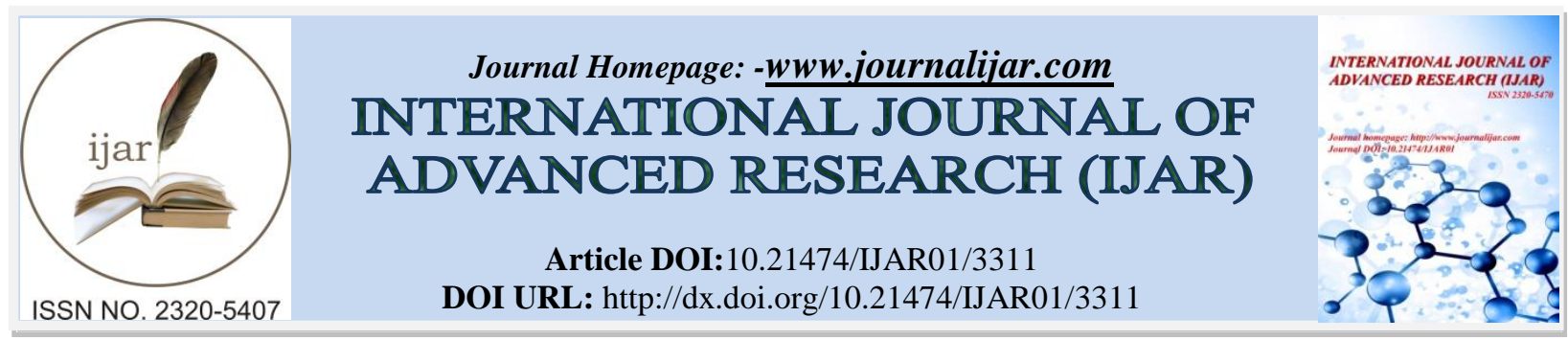

RESEARCH ARTICLE

\title{
HIGH VELOCITY PENETRATING FOREIGN BODY SUSTAINED IN PTERYGOPALATINE FOSSA, CASE REPORT.
}

\author{
Ridha F. Albahrani ${ }^{1}$, Ali S. Albrahim ${ }^{1}$ and Hussain A. Alabdulal ${ }^{2}$. \\ 1. Medical Intern, ImamAbdulrahman Bin Faisal University. \\ 2. Medical Intern, Arabian gulf university.
}

\section{Manuscript Info}

Manuscript History

Received: 22 December 2016

Final Accepted: 26 January 2017

Published: February 2017

\section{Abstract}

Craniofacial penetrating foreign body involving the pterygopalatine fossa is a rare condition, it present $2.17 \%$ of all head and neck trauma. It could be life-threatening due to injury of vital surrounding structure such as eyes, carotid arteries and cranial nerves. $35 \mathrm{We}$ present a case of a sustained foreign body in the pterygopalatine fossa in a 3-year-old boy sparing the eyes and vasculature. The object was a gun shoot.it was removed successfully using endoscopic approach with no complication.

Copy Right, IJAR, 2017,. All rights reserved.

\section{Introduction:-}

Skull base penetrating foreign body is a rare condition. $\underline{3} \underline{5}$ In our case, the foreign body was found as sustained foreign body in pterygopalatine sparing the eyes and vasculature, it was removed successfully using endoscopic approach with no complication.

Here we are presenting a case of accidental gun shoot victim who presented to our university hospital in Saudi Arabia.

\section{Case:-}

3 years old Saudi boy was a victim of accidental gun shoot in the right dorsum of his nose. They presented to a local hospital in Saudi Arabia with excessive bleeding at the site of bullet not associated with any neurological symptoms nether irritability or vomiting. 15 days later, they were referred to our university institute because they do not have the facilities of skull base surgery. The patient's status upon referral was stable the bleeding was stopped and the wound wasn't showing any discharge, sparing the eyes and craniofacial vasculature,

Patient's hemoglobin and blood indices all were in the normal ranges. CTscan of head and neck showedforeign body located in right pterygopalatine fossa situated in the right sphenoid bone within right foramen of rotundum area(figure 1), CT angiogram showed no vascular insult with normal course of internal and external carotid arteries. Even though the patient was asymptomatic, a decision of surgical removal was done and accordingly Trans-nasal endoscopic removal was done successfully under general anesthesia with no complication. Post-operative, the patient was vitally stable doing well with no neurological deficit. 


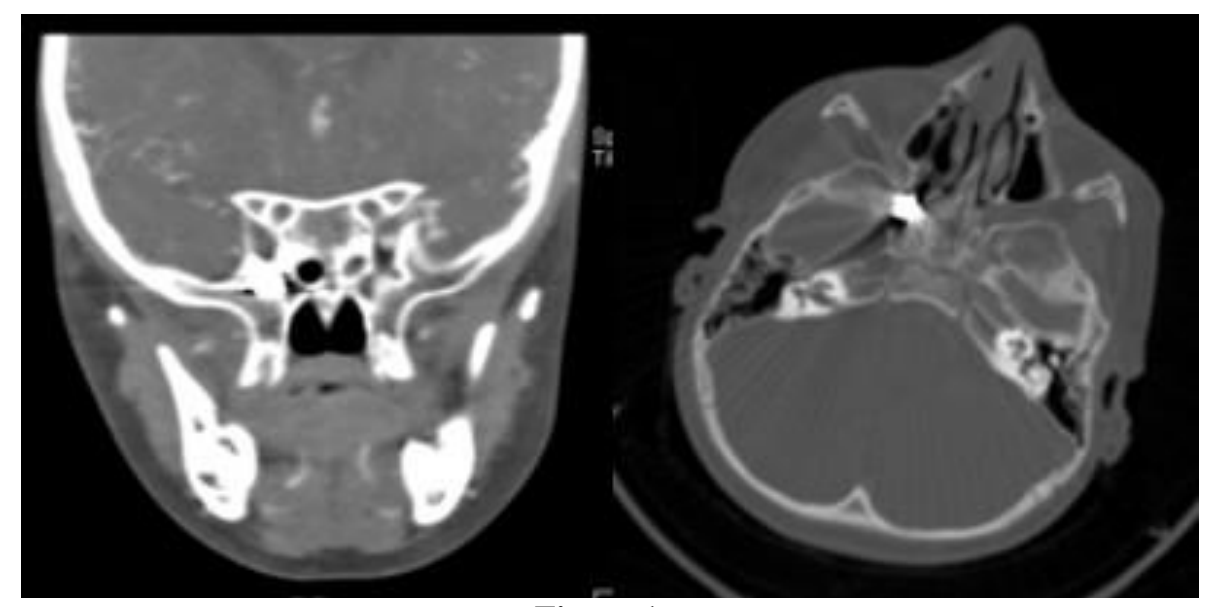

Figure 1:-

\section{Discussion:-}

Skull base penetrating foreign body is a rare condition, it present $2.17 \%$ of all head and neck trauma. It could be life threatening due to injury of vital surrounding structure such as eyes, carotid arteries and cranial nerves. $\underline{35}$ Compared to our case, the carotid arteries \& cranial nerves were spared. CT scan is the method of choice to diagnose and localize the foreign body, however wood particles can be missed, in this case MRI can be used, CT angiogram should be performed to rule out vasculature injury. 56

The metallic foreign body has to be removed even in asymptomatic patient because it can lead to infection \&is believed to be a cause of chronic irritation and could be cancerous due to epithelial alteration. 3 Endoscopic and open surgeries both are the available approaches of removal, however endoscopic approach was described to be associated with less complications. $\underline{4}$ Prognosis and timing of removal is contingent on the patient's overall status.15Compared to our case, trans-nasal endoscopic approach was done \& the foreign body was removed with no complications.

\section{Conclusion:-}

Penetrating metallic foreign body has to be removed to prevent infection \& chronic irritation. The endoscopic approach of removal is preferred due to less complication compared to open surgery.

\section{References:-}

1. Wu X $\mathrm{X}^{1}, \mathrm{Li} \mathrm{A}, \mathrm{Tan} \mathrm{J}, \mathrm{Ou} \mathrm{X}$. Removal of orbital-maxillary sinus-pterygopalatine fossa foreign body with external and endoscopic combined approach.JCraniofac Surg. 2014 Jul;25.

2. Badran $\mathrm{K}^{1}$, Sudhoff H, Gray R. An unusual air gun injury to the ethmoidsinus.Eur Arch Otorhinolaryngol. 2007 Oct.

3. Mathews, Alex; Nair, Arun; Tandon, Shantanu; Souza, Ophelia DPenetrating foreign body in the maxillary sinus and pterygopalatine fossa: Report of a rare case. Internet Journal of Head \& Neck Surgery;2010.

4. Komotar RJ, Starke RM, Raper DM, Anand VK, Schwartz TH. Endoscopic endonasal versus open repair of anterior skull base CSF leak, meningocele, and encephalocele: a systematic review of outcomes.Journal of Neurological Surgery A: Central European Neurosurgery. 2013;74(4):239-250.

5. Bharat Yarlagadda, M.D.,1ScharukhJalisi, M.D.,1,2 Peter Burke, M.D.,3 and Michael Platt, M.D. Retrieval of projectile foreign bodies from the paranasal sinuses and skull base. Am J Rhinol Allergy. May 1, 2012.

6. Jusué-Torres $\mathrm{I}^{1}$, Burks $\mathrm{SS}^{1}$, Levine $\mathrm{CG}^{2}$, Bhatia $\mathrm{RG}^{3}$, Casiano $\mathrm{R}^{2}$, Bullock $\mathrm{R}^{4}$. Wooden Foreign Body in the Skull Base: How Did We Miss It?WorldNeurosurg. 2016 Aug

7. Brandes $\mathrm{A}^{1}$, GehrkeG.Foreign body removal from the orbit and skull base. Mund Kiefer Gesichtschir. 1998 May 